\title{
Comparative Efficacy and Safety Evaluation of Tramadol plus Diclofenac versus Tramadol plus Paracetamol in a Subgroup of Indian Patients with Moderate to Severe Acute Musculoskeletal Pain: A Phase III, 5 Day Open Label Study
}

Gauri Billa ${ }^{1 *}$, Ajay S Chandanwale², Subramanian Sundar ${ }^{3}$, Kaliaperumal Latchoumibady ${ }^{4}$, Swati Biswas5

${ }^{1}$ Medical Advisor, Abbott Healthcare Pvt Ltd, 1st floor, D Mart Bldg, Mulund-Goregaon Link Road, Mumbai.

${ }^{2}$ Department of Orthopedics\& Traumatology, Byramjeejeejeebhoy Medical College and. Sassoon General Hospital, Pune.

${ }^{3}$ Consultant orthopedic surgeon, Vasantha Subramanian Hospital, Chennai, Tamil Nadu.

${ }^{4}$ Consultant orthopedic surgeon, Vijay Hospital, Pondicherry.

${ }^{5}$ Chief Medical Advisor, Abbott Healthcare Pvt Ltd, 1st floor, D Mart Bldg, Mulund-Goregaon Link Road, Mumbai.

Received: May 30, 2016; Accepted: October 5, 2016; Published: January 6, 2017

*Corresponding author: Gauri Billa, Medical Advisor, Abbott Healthcare Pvt Ltd, 1st floor, D Mart Bldg, Mulund-Goregaon Link Road, Mumbai 400080, India, E-mail: gauri.billa@abbott.com

\begin{abstract}
Objective: To evaluate safety and efficacy of Fixed Dose Combination (FDC) of tramadol+diclofenac vs. FDC of tramadol+paracetamol in patients with Acute Musculo Skeletal Pain (AMSP).

Methods: This was a randomized, open label, comparative, parallel group, and multicentric trial. 52 patients with AMSP were randomized to receive either of the two treatments: Tramadol hydrochloride $50 \mathrm{mg}$ immediate release/diclofenac sodium $75 \mathrm{mg}$ sustained release (one tablet twice daily-Group A) or tramadol hydrochloride $37.5 \mathrm{mg} /$ paracetamol $325 \mathrm{mg}$ (two tablets every 4-6 hours upto a maximum of 8 tablets daily-Group B) for 5 days. The primary efficacy endpoint was reduction in pain intensity from baseline at day 3 and day 5 as assessed by Visual Analogue Scale (VAS) score. Secondary endpoints were reduction in swelling and inflammation from baseline. Global assessment of tolerability by patients was done on day 5 .
\end{abstract}

Results: Fifty one patients completed the study. At day five, reduction in VAS $(p=0.002)$, pain at rest $(p<0.0001)$, pain on movement $(\mathrm{p}=0.003)$ and mean score of inflammation $(p=0.001$ ) was significantly better in group A compared to group B. Reduction in swelling and total score of inflammation was superior in group 1 at day three and five. Global assessment of tolerability by patients was good in $92.31 \%$ and $24 \%$ patients in group A and B respectively $(\mathrm{p}<0.0001)$. No serious adverse event was reported.

Conclusion: FDC of tramadol/diclofenac showed significantly greater reduction in pain intensity and was well tolerated as compared to tramadol/paracetamol in patients suffering from AMSP.

Keywords: Acute musculoskeletal pain; Combination analgesics, Tramadol plus diclofenac combination

\section{Introduction}

Pain either alone or associated with other conditions is one of the main reasons for consultations in general practice [1]. Pain represents a global health problem with estimated about $20 \%$ adults suffering from pain [2]. Musculoskeletal conditions, one of the causes of pain are also a significant health problem worldwide. Patients of all age with acute musculoskeletal pain are frequently seen in clinical practice which needs to be successfully treated to avoid progression into chronic conditions [3]. Different analgesic agents from opioid and non-opioid group are available for the treatment of pain. Tramadol hydrochloride is a centrally acting analgesic which acts as a weak atypical opioid agonist and monoamine neurotransmitter reuptake inhibitor $[4,5]$. Thus, the analgesia provided by tramadol is a result of both opioid and nonopioid mechanisms [6] which appear to act synergistically [7]. Paracetamol is rapidly acting non-opioid analgesic [8] routinely used in clinical practice. It is effective for the treatment of moderate pain [9]. Single analgesic agent can not treat all types of pain [10], hence the analgesics are often selected based on the difference in pain severity and duration of pain [1]. Combination of analgesic agents with complementary mechanisms may provide higher efficacy because of the action on multiple pain-inhibiting pathways [10] and a better safety compared to individual agents $[10,11]$. Fixed Dose oral Combination (FDC) of tramadol 37.5 $\mathrm{mg}$ plus paracetamol $325 \mathrm{mg}$ is indicated for the symptomatic treatment of moderate to severe pain [5]. The combination has been shown to provide supra-additive analgesic effects [12] and well studied in acute moderate to severe pain.

Non-Steroidal Anti-Inflammatory agent (NSAID) can also be combined with an opioid for the management of moderate 
to severe acute pain because of their different mechanisms of action [13]. Similar to paracetamol [9], NSAIDs also have opioid sparing action [14]. Diclofenac is a well studied and commonly used NSAID having analgesic, anti-inflammatory, and antipyretic properties. Multiple mechanisms of action including inhibition of thromboxane-prostanoid receptor, arachidonic acid release and uptake, lipoxygenase enzymes, and activation of the nitric oxide-cGMP antinociceptive pathway by diclofenac suggests better profile compared to other NSAIDs [15]. A fixed dose combination of immediate release tramadol plus sustained release diclofenac has been developed with the rationale of providing better analgesia in moderate to severe pain due to different and complimentary mechanisms of action and also to provide immediate as well as sustained pain relief.

The objective of this study was to evaluate the efficacy and safety of tramadol -diclofenac versus tramadol-paracetamol FDC in Indian patients with acute musculoskeletal pain.

\section{Methods}

A randomized, open label, comparative, parallel group, multi-centre trial was conducted to evaluate the efficacy and safety of the immediate release tramadol $50 \mathrm{mg}$ plus sustained release diclofenac $75 \mathrm{mg}$ FDC vs tramadol $37.5 \mathrm{mg}$ plus paracetamol $325 \mathrm{mg}$ FDC in treatment of patients with moderate to severe pain due to Acute Musculoskeletal Pain (AMSP), acute flare of osteoarthritis, acute flare of rheumatoid arthritis, or postoperative pain in Indian patients. The results of this study are published in 2014[13]. In this paper, the subgroup analysis of comparative efficacy and safety of the two combinations in acute musculoskeletal conditions is presented. Adult subjects $>18$ years and $<70$ years with clinical diagnosis of acute musculoskeletal pain (tendonitis, bursitis, synovitis) having VAS [16] score $>50$ $\mathrm{mm}$ during last five days prior to the baseline visit were enrolled. Pregnant women, nursing mothers and those hypersensitive to tramadol, diclofenac or paracetamol were excluded. Patients with active peptic ulcer, gastrointestinal bleeding, having history of peptic ulcers, gastric irritations and NSAID intolerance, abnormal renal and liver functions and on any other treatment medications such as NSAIDs, corticosteroids, and opioid analgesics or alternate therapy (physiotherapy and acupuncture) were excluded from the study. During the treatment period, unbearable pain was treated with rescue medication diclofenac.

The enrolled subjects were treated with immediaterelease tramadol hydrochloride $50 \mathrm{mg}$ plus sustained-release diclofenac sodium $75 \mathrm{mg}$ one FDC tablet, twice daily or tramadol hydrochloride $37.5 \mathrm{mg}$ and paracetamol $325 \mathrm{mg}$ two FDC tablets every 4-6 hours, up to a maximum of eight tablets daily. The duration of treatment was five days. Randomization was done based on a PC based program Rando Version $2.0{ }^{\circledR}$.

The patients were assessed at baseline, on day 3 and day 5 of treatment, on the following parameters: pain intensity, swelling, inflammation, and use of rescue medications. The primary efficacy parameter was reduction in pain intensity from baseline to day three and day five. The pain intensity was measured with a 0-100 mm VAS scale (for overall pain, pain at rest, and pain on movement). Pain relief was measured at the end of five day treatment. The global assessment of efficacy and tolerability was done at the end of study while laboratory investigations were performed at screening, baseline and day five.

Adverse events reported during the study period, abnormalities during physical examination, vital signs and laboratory analysis (haematological and biochemistry) were considered for safety analysis. Tolerability was assessed on a three point scale (good-side effects mild or not observed; moderate-side effects of moderate intensity; poor-severe side effects or discontinuation) and efficacy on a five point scale (poor, satisfactory, good, very good and excellent) at the end of the therapy.

The study protocol and informed consent form were approved by respective hospital's ethics committee. The study was conducted in accordance with the Declaration of Helsinki (1964). The patients reviewed and voluntarily signed the informed consent form before enrolment in the study.

\section{Statistical analysis}

Two treatment groups were evaluated for comparing demographic data and baseline symptom scores. Efficacy analysis was done with per-protocol population while safety analysis was done with intent-to-treat population. Quantitative data was analyzed using student's ' $t$ ' test \&analysis of variance (ANOVA), and ranking/qualitative data was analyzed using Mann-Whitney ' $U$ ' test and the Kruskall-Wallis test. Proportions were compared using the Chi-square test. P values $<0.05$ were considered statistically significant.

\section{Results}

A total of 52 patients were enrolled out of whom 51 completed the study. One patient from tramadol-paracetamol group lost to follow up. The baseline demographics are presented in table 1. No significant difference was seen in the gender between two groups. Other baseline parameters i.e. pulse rate, systolic and diastolic blood pressure were also comparable in both groups (table 1).

The reduction in the intensity of overall pain was assessed using VAS scale of $0-100 \mathrm{~mm}$. The scores were compared between two groups. No significant difference in the mean or percentage change in the VAS score was observed between two groups at day 3 (table 2 and figure $1 ; \mathrm{p}=0.233$ ). However the difference in mean and percentage change in the VAS score was significant at day five (table 2 and figure $1 ; \mathrm{p}=0.002$ ) favouring tramadoldiclofenac over tramadol- paracetamol combination.

The mean and percentage change in the VAS score for pain at rest was not significantly different between two groups at day three (table 2 and figure 2; $\mathrm{p}=0.11$ ). At day five, combination of tramadol- diclofenac resulted in significant improvement compared to tramadol-paracetamol combination (table 2 and figure $2 ; \mathrm{p}<0.0001$ ).

Similarly, for pain on movement, the mean or percentage difference in VAS score was not significant between two groups 
at day three (table 2 and figure $3 ; \mathrm{p}=0.388$ ). At day five, tramadoldiclofenac combination was significantly better in reducing mean and percentage VAS score compared to tramadol-paracetamol combination (table 2 and figure $3 ; \mathrm{p}=0.003$ ).

The mean and percentage reduction of swelling was significantly superior with tramadol -diclofenac compared to tramadol-paracetamol both at day three and five (table 2; day three $\mathrm{p}=0.002$; day $5 \mathrm{p}=0.012$ ) while improvement in the mean score of inflammation was significantly better with tramadoldiclofenac combination at day 5 (table 2; p=0.001). The improvement in the total score of inflammation was significantly superior to tramadol-paracetamol combination at both visits (table 2; day three $\mathrm{p}=0.004$; day five $\mathrm{p}<0.0001$ ).

Overall, a total of $15.38 \%$ and $32 \%$ patients receiving tramadol-diclofenac and tramadol-paracetamol respectively received concomitant medication. One day three and five there was no difference for use of concomitant medication between two groups.

Global assessment of efficacy data evaluated by both

Table 1: Baseline characteristics

\begin{tabular}{|c|c|c|c|}
\hline & $\begin{array}{l}\text { Tramadol + } \\
\text { Diclofenac } \\
(n=26)\end{array}$ & $\begin{array}{c}\text { Tramadol + } \\
\text { Paracetamol } \\
(n=25)\end{array}$ & $P$ value \\
\hline $\begin{array}{l}\text { Age (Years) } \\
\text { mean (SEM) }\end{array}$ & $44.23(2.56)$ & $46.32(2.82)$ & $\mathrm{P}=0.586$ \\
\hline $\begin{array}{c}\text { Sex } \\
\text { Male n (\%) } \\
\text { Female n (\%) }\end{array}$ & $\begin{array}{l}16(61.54 \%) \\
10(38.46 \%)\end{array}$ & $\begin{array}{l}12(48 \%) \\
13(52 \%)\end{array}$ & $\begin{array}{l}\chi^{2}, 0.943 \\
P=0.331\end{array}$ \\
\hline $\begin{array}{l}\text { Vital signs mean } \\
\text { (SEM) } \\
\text { Pulse (per min.) } \\
\text { Systolic BP (mm } \\
\text { Hg) } \\
\text { Diastolic BP (mm } \\
\text { Hg) }\end{array}$ & $\begin{array}{c}76.92(1.38) \\
120.46(1.37) \\
77.38(1.05)\end{array}$ & $\begin{array}{c}75.28(1.08) \\
121.12(1.84) \\
76.16(1.32)\end{array}$ & $\begin{array}{l}\mathrm{P}=0.355 \\
\mathrm{P}=0.774 \\
\mathrm{P}=0.470\end{array}$ \\
\hline
\end{tabular}

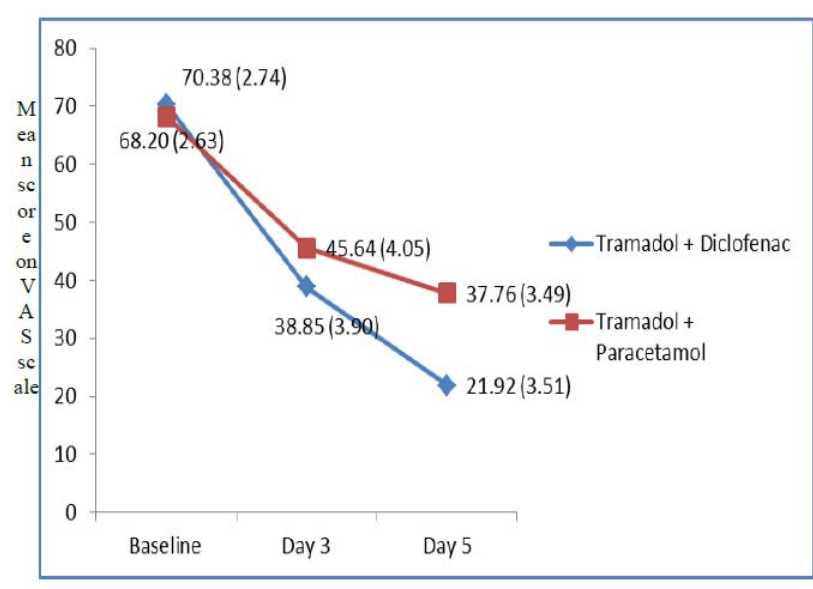

Figure 1: Comparison of mean (SEM) VAS score for overall pain between tramadol-diclofenac and tramadol-paracetamol
Table 2: Comparison of efficacy parameters between between tramadol-diclofenac and tramadol-paracetamol

\begin{tabular}{|c|c|c|c|}
\hline & $\begin{array}{c}\text { Tramadol + } \\
\text { Diclofenac } \\
(\mathbf{n = 2 6 )}\end{array}$ & $\begin{array}{c}\text { Tramadol + } \\
\text { Paracetamol } \\
(\mathbf{n = 2 5})\end{array}$ & $\begin{array}{c}\text { 't' test } \\
\text { P value }\end{array}$ \\
\hline \multicolumn{3}{|c|}{ Mean score for overall pain on 0-100 VAS scale } & \\
\hline Baseline, mean (SEM) & $70.38(2.74)$ & $68.20(2.63)$ & 0.568 \\
\hline $\begin{array}{c}\text { Day 3, mean change (\% } \\
\text { change) }\end{array}$ & $\begin{array}{c}-31.54 \\
(-44.81 \%)\end{array}$ & $-22.56(-33.08 \%)$ & 0.233 \\
\hline $\begin{array}{c}\text { Day 5, mean change (\% } \\
\text { change) }\end{array}$ & $\begin{array}{c}-48.46 \\
(-68.85 \%)\end{array}$ & $-30.44(-44.63 \%)$ & 0.002 \\
\hline \multicolumn{4}{|c|}{ Mean score for pain at rest on 0-100 VAS scale } \\
\hline Baseline, mean (SEM) & $56.92(2.34)$ & $56.80(2.50)$ & 0.971 \\
\hline $\begin{array}{c}\text { Day 3, mean change (\% } \\
\text { change) }\end{array}$ & $\begin{array}{c}-26.15 \\
(-45.95 \%)\end{array}$ & $-17.00(-29.93 \%)$ & 0.11 \\
\hline Day 5, mean change (\% \\
change)
\end{tabular}

Mean score for pain on movement on 0-100 VAS scale

\begin{tabular}{|c|c|c|c|}
\hline Baseline, mean (SEM) & $76.92(2.06)$ & $74.80(2.17)$ & 0.481 \\
\hline $\begin{array}{c}\text { Day 3, mean change (\% } \\
\text { change) }\end{array}$ & $\begin{array}{c}-33.08 \\
(-43 \%)\end{array}$ & $-26.36(-35.24 \%)$ & 0.388 \\
\hline $\begin{array}{c}\text { Day 5, mean change (\% } \\
\text { change) }\end{array}$ & $\begin{array}{c}-50.19 \\
(-65.25 \%)\end{array}$ & $-33.16(-44.33 \%)$ & 0.003 \\
\hline
\end{tabular}
change)

Mean score for swelling

\begin{tabular}{|c|c|c|c|}
\hline Baseline, mean (SEM) & $1.80(0.21)$ & $1.68(0.18)$ & 0.665 \\
\hline $\begin{array}{c}\text { Day 3, mean change (\% } \\
\text { change) }\end{array}$ & $-0.92(-51.11)$ & $-0.22(-13.19)$ & 0.002 \\
\hline $\begin{array}{c}\text { Day 5, mean change (\% } \\
\text { change) }\end{array}$ & $-1.44(-80 \%)$ & $-0.85(-50.40)$ & 0.012
\end{tabular}

\section{Mean score for Inflammation}

\begin{tabular}{|c|c|c|c|}
\hline Baseline, mean (SEM) & $1.84(0.19)$ & $1.54(0.21)$ & 0.293 \\
\hline $\begin{array}{c}\text { Day 3, mean change (\% } \\
\text { change) }\end{array}$ & $-1.04(-56.52)$ & $-0.50(-32.43 \%)$ & 0.232 \\
\hline $\begin{array}{c}\text { Day 5, mean change (\% } \\
\text { change) }\end{array}$ & $\begin{array}{c}-1.60 \\
(-86.96 \%)\end{array}$ & $-0.79(-51.35 \%)$ & 0.001
\end{tabular}

Total score for Inflammation

\begin{tabular}{|c|c|c|c|}
\hline Baseline, mean (SEM) & $3.64(0.32)$ & $3.24(0.30)$ & 0.368 \\
\hline $\begin{array}{c}\text { Day 3, mean change (\% } \\
\text { change) }\end{array}$ & $\begin{array}{c}-1.96 \\
(-53.85 \%)\end{array}$ & $-0.74(-22.84 \%)$ & 0.004 \\
\hline $\begin{array}{c}\text { Day 5, mean change (\% } \\
\text { change) }\end{array}$ & $\begin{array}{c}-3.04 \\
(-83.52 \%)\end{array}$ & $-1.70(-52.42 \%)$ & $<0.0001$ \\
\hline
\end{tabular}

physician and patient is shown in table 3 . The results showed that according to the global assessment of efficacy as evaluated by physician $88 \%$ patients receiving tramadol-diclofenac had very good to excellent efficacy while only $24 \%$ patients in the tramadol-paracetamol had very good to excellent efficacy ( table 3 ; $\mathrm{p}<0.0001$ ). About $96 \%$ of patients who received tramadoldiclofenac had very good to excellent efficacy while $20 \%$ who received tramadol-paracetamol had very good to excellent efficacy ( table 3; p<0.0001).

Table 4 shows the global assessment of tolerability evaluated by physicians and patients. According to the global assessment of tolerability evaluated by physician $88.46 \%$ patients who 
received tramadol-diclofenac had good tolerability while $88 \%$ patients in the tramadol-paracetamol group had moderate to good tolerability ( table $3 ; \mathrm{p}<0.0001$ ). The global assessment of tolerability as evaluated by patients was good in $92.31 \%$ and $24 \%$ patients who received tramadol-diclofenac and tramadolparacetamol respectively ( table $3 ; \mathrm{p}<0.0001$ )

The overall incidence of adverse events was $11.54 \%$ and $24 \%$ with tramadol-diclofenac and tramadol-paracetamol respectively. The rate of adverse events was less in tramadol-diclofenac group on both days (day 3: $7.69 \%$ vs $20 \%$; day 5: $11.54 \%$ vs $16 \%$; table 5)). All the adverse events were gastrointestinal (gastritis, nausea and vomiting) in nature except drowsiness reported by one patient receiving tramadol-paracetamol on day three. No serious adverse event was reported in this study.

\section{Discussion}

The combination of diclofenac and tramadol provides advantage of different mechanisms of action with potential for wider spectrum of pain relief. Our group has recently published

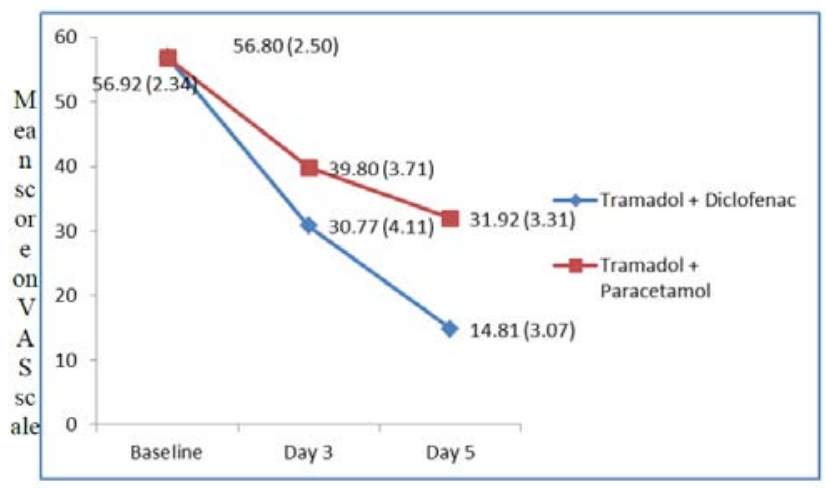

Figure 2: Comparison of mean (SEM) VAS score for pain at rest between tramadol-diclofenac and tramadol-paracetamol

Table 3: Comparison of global assessment of efficacy between tramadol-diclofenac and tramadol-paracetamol

\begin{tabular}{|c|c|c|}
\hline & $\begin{array}{c}\text { Tramadol + } \\
\text { Diclofenac (n=26) }\end{array}$ & $\begin{array}{c}\text { Tramadol + } \\
\text { Paracetamol (n=25) }^{*}\end{array}$ \\
\hline \multicolumn{2}{|c|}{ Global assessment of efficacy by } \\
physician
\end{tabular}

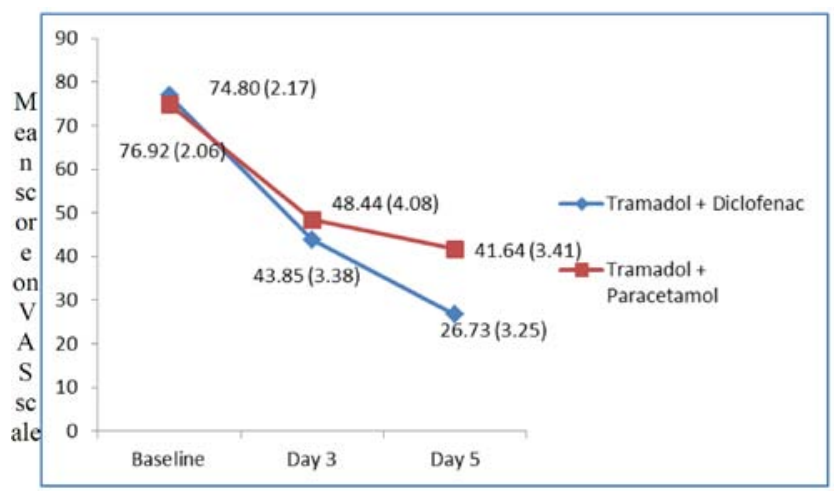

Figure 3: Comparison of mean (SEM) VAS score for pain on movementbetween tramadol-diclofenac and tramadol-paracetamol

Table 4: Comparison of global assessment of tolerability between tramadol-diclofenac and tramadol-paracetamol

$$
\text { Tramadol + }
$$

Tramadol +

Diclofenac $(n=26)$

Paracetamol $(n=25)$

Global assessment of tolerability by physician ${ }^{a}$

\begin{tabular}{|c|c|c|}
\hline Poor, n (\%) & $1(3.85 \%)$ & $3(12.00 \%)$ \\
\hline Moderate, n (\%) & 2 (7.69\%) & $15(60.00 \%)$ \\
\hline Good, n (\%) & $23(88.46 \%)$ & $7(28.00 \%)$ \\
\hline \multicolumn{3}{|c|}{ Global assessment of tolerability by patient ${ }^{b}$} \\
\hline Poor, n (\%) & $1(3.85 \%)$ & $7(28.00 \%)$ \\
\hline Moderate, n (\%) & $1(3.85 \%)$ & $12(48.00 \%)$ \\
\hline Good, n (\%) & $24(92.31 \%)$ & $6(24.00 \%)$ \\
\hline
\end{tabular}

Table 5: Comparative incidence of adverse events between tramadoldiclofenac and tramadol-paracetamol

\begin{tabular}{|c|c|c|}
\hline & $\begin{array}{c}\text { Tramadol + } \\
\text { Diclofenac (n=26) }\end{array}$ & $\begin{array}{c}\text { Tramadol + } \\
\text { Paracetamol (n=25) }\end{array}$ \\
\hline & Day 3 \\
\hline Nausea, n (\%) & $1(3.85)$ & $2(8 \%)$ \\
\hline Vomiting, n (\%) & - & $1(4 \%)$ \\
\hline Gastritis, n (\%) & $1(3.85)$ & $1(4 \%)$ \\
\hline Drowsiness, n (\%) & - & $1(4 \%)$ \\
\hline & Day 5 \\
\hline Nausea, n (\%) & $2(7.69)$ & $2(8 \%)$ \\
\hline Vomiting, n (\%) & - & $1(4 \%)$ \\
\hline Gastritis, n (\%) & $1(3.85)$ & $1(4 \%)$ \\
\hline
\end{tabular}

a phase three Indian study which demonstrated that tramadoldiclofenac FDC results in significantly greater analgesia compared to tramadol-paracetamol in patients with moderate to severe pain due to acute musculoskeletal conditions, postoperative pain following orthopaedic surgery, or acute flare of osteoarthritis and rheumatoid arthritis [13]. In this paper, we compared the safety and efficacy of tramadol-diclofenac with tramadol-paracetamol, as an analgesic agent in subgroup population of moderate to 
severe pain in acute musculoskeletal conditions. The results of this subgroup analysis confirm that tramadol and diclofenac is the rational combination for management of moderate to severe pain in acute musculoskeletal conditions.

In acute musculoskeletal pain, tramadol-diclofenac administration resulted in greater reduction of swelling and total score of inflammation compared to tramadol-paracetamol both at day three and five. Diclofenac is a non-steroidal antiinflammatory agent [16]. The anti-inflammatory property of diclofenac provides an advantage in acute inflammatory musculoskeletal pain as paracetamol does not have any effect on the inflammatory mediators [17].

The VAS score for overall pain was significantly reduced after combination therapy of tramadol and diclofenac. Mitra et al [18] have showed that diclofenac-tramadol and diclofenacparacetamol combinations are effective in providing postoperative pain control after caesarean section. The investigators demonstrated that the overall efficacy of diclofenac-tramadol combination is better than diclofenac-paracetamol.

Similarly, another comparative study has evaluated the efficacy and safety of diclofenac-tramadol [19]. Compared to diclofenac alone, the combination has been shown to provide faster and longer pain relief in patients after unilateral hallux valgus surgery. The combination was found to be well tolerated in acute inflammatory pain of moderate to severe intensity [19].

We did not find any comparative study of tramadol-diclofenac combination in acute musculoskeletal pain. In this regards, our study results provide unique insights about efficacy and safety of combination in subset of population with moderate to severe pain.

Both the combinations were well tolerated by patient population in our study. The incidence of adverse events was less in patients receiving the tramadol-diclofenac combination compared with those receiving the tramadol-paracetamol combination, on both day 3 and day 5 . The difference in rate of adverse events can partly be explained by higher number of patients receiving concomitant medication in tramadolparacetamol group. The dose of tramadol in FDC with diclofenac sodium was $100 \mathrm{mg}$ per day versus 150-225 (up to maximum of $300 \mathrm{mg}$ ) mg per day in FDC with paracetamol. Higher dose of tramadol with paracetamol combination could be another possibility for more adverse events.

In the study conducted by Mitra et al [18], tramadol-diclofenac was associated with comparable side effects with tramadolparacetamol and higher incidence of post-operative nausea. Use of rescue analgesic intake was similar between two groups $(\mathrm{P}=$ 0.872). In our study also, the use of concomitant medication was similar on day three and five.

The difference was in the route of administration. In this study tramadol was used as oral medication while Mitra et al [18] used intravenous tramadol.
All the adverse events in our study were mild to moderate in nature, with self-limiting gastrointestinal adverse events (gastristis, nausea and vomiting) being most common.

This study has some limitations. Small sample size limits the extrapolation of the results to entire population with acute musculoskeletal pain. The results of this paper are limited only to patients with acute musculoskeletal pain. A separate subgroup analysis needs to be conducted to see whether similar trend of results were seen in acute flare of osteoarthritis, acute flare of rheumatoid arthritis and postoperative pain. The study was conducted in controlled setting to evaluate the role of co morbidities in these patients; a study in real-world settings is required. Lastly, though the study was conducted in controlled setting with randomization, an open label study design leaves an area for suspecting bias.

\section{Conclusion}

The tramadol-diclofenac combination resulted in significantly greater reduction in VAS scores for overall pain, pain at rest and pain on movement on day five compared to tramadol-paracetamol combination. Mean score for swelling and total score for inflammation, was significantly better with tramadol-diclofenac combination compared with the tramadolparacetamol combination both at day three and five. Both the formulations caused mainly GI side effects of mild to moderate intensity without any serious adverse event warranting discontinuation of treatment.

\section{Acknowledgement}

The authors of this study wish to thank Dr. Anant D Patil for assistance in writing and editing the manuscript.

\section{Declaration}

Financial support for the project, along with the study drug, Dura pain ${ }^{\circledR}$ (tramadol $50 \mathrm{mg}$ immediate release with diclofenac sodium $75 \mathrm{mg}$ sustained release), was provided by Abbott Healthcare Pvt Ltd, India. Pvt Ltd, India. B Gauri and B Swati are employees of Abbott Healthcare Pvt Ltd, India. The other authors report no conflict of interest.

Trial registration number: CTRI/2011/091/000150 [Registered on: 01/02/2011]

\section{References}

1. Leung L. From ladder to platform: a new concept for pain management. J Prim Health Care. 2012;4(3):254-258.

2. Goldberg D, McGee SJ. Pain as a global public health priority. BMC Public Health. 2011;11:770. doi: 10.1186/1471-2458-11-770.

3. Spearing N, March L, Bellamy N, Bogduk N, Brooks PM. Management of acute musculoskeletal pain. APLAR Journal of Rheumatology. 2005;8(1):5-15. DOI: 10.1111/j.1479-8077.2005.00114.x.

4. Rawal N, Macquaire V, Catala E, Berti M, Costa R, Wietlisbach M. Tramadol/paracetamol combination tablet for postoperative pain following ambulatory hand surgery: a double-blind, doubledummy,randomized, parallel-group trial. Journal of Pain Research. 2011;4:103-110. doi:10.2147/JPR.S16760. 
5. Dhillon S. Tramadol/paracetamol fixed-dose combination: a review of its use in the management of moderate to severe pain. Clin Drug Investig. 2010;30 (10):711-38. doi: 10.2165/11205830-00000000000000 .

6. Raffa RB, Friderich E, Reimann W, Shank RP, Codd EE, Vaught JL. Opioid and nonopioid components independently contribute to the mechanism of action of tramadol, an 'atypical' opioid analgesic. J PharmacolExpTher. 1992;260 (1):275-285

7. Lehmann KA. Tramadol in acute pain. Drugs1997; 53; (Suppl 2):2553.

8. Parfitt K, editor. Analgesics, anti-inflammatory drugs and antipyretics. In: Martindale, The Complete Drug Reference, 32nd edition. London, UK: Pharmaceutical Press; 1999;1-91.

9. Kehlet H, Werner MU. Role of paracetamol in the acute pain management. Drugs2003;63(2):15-22.

10. Raffa RB. Pharmacology of oral combination analgesics: rational therapy for pain. J Clin Pharm Ther. 2001;26(4):257-264.

11. Desmeules J, Rollason V, Piguet V, Dayer P. Clinical pharmacology and rationale of analgesic combinations. Eur J Anaesthesiol 2003;20(28):7-12.

12. Filitz J, Ihmsen H, Gunther W, Troster A, Schwilden H, Schuttler J, et al Supra-additive effects of tramadol and acetaminophen in a human pain model. Pain. 2008;136(3):262-270. DOI:10.1016/j.pain.2007.06.036.

13. Chandanwale AS, Sundar S, Latchoumibady K, Biswas S, Gabhane M, Naik $M$ et al. Efficacy and safety profile of combination of tramadoldiclofenac versus tramadol-paracetamolin patients with acute musculoskeletal conditions, postoperative pain, and acute flare of osteoarthritisand rheumatoid arthritis: a Phase III, 5-day open-label study. Journal of Pain Research. 2014;7:455-463. doi: 10.2147/JPR. S67817.

14. Hyllested M, Jones S, Pederson JL, Kehlet H. Comparative effects of paracetamol, NSAIDs of their combination in post-operative pain management: a qualitative review. British Journal of Anesthesia. 2002;88(2):199-214.

15.Gan TJ. Diclofenac: an update on its mechanism of action and safety profile. Curr Med Res Opin. 2010;26(7):1715-1731. doi: 10.1185/03007995.2010.486301.

16. Hawker GA, Mian S, Kendzerska T, French M. Measures of adult pain: Visual Analog Scale for Pain (VAS Pain), Numeric Rating Scale for Pain (NRS Pain), McGill Pain Questionnaire (MPQ), Short-Form McGill Pain Questionnaire (SF-MPQ), Chronic Pain Grade Scale (CPGS), Short Form-36 Bodily Pain Scale (SF-36 BPS), and Measure of Intermittent and Constant Osteoarthritis Pain (ICOAP). Arthritis Care Res. 2011;63(S11):S240-S252. doi: 10.1002/acr.20543.

17. Fowler PD. Aspirin, paracetamol and non-steroidal anti-inflammatory drugs. A comparative review of side effects. Med Toxicol Adverse Drug Exp. 1987;2(5):338-366.

18. Mitra S, Khandelwal P, Sehgal A. Diclofenac-tramadol vs. diclofenacacetaminophen combinations for pain relief after caesarean section. ActaAnaesthesiolScand. 2012;56(6):706-711. doi: 10.1111/j.13996576.2012.02663.x.

19. Auad A, Cadena L, Garzón LA, et al. Efficacy and safety of the fixed combination diclofenac/tramadol in acute pain: randomized clinical trial phase III, double-blind, controlled. Iberoamericana Rev Pain. 2009;4:13-23. 